\begin{tabular}{|c|c|c|}
\hline UÁQUIRI & PPG \\
\hline & Revista do Programa de Pós-Graduação em Geografia \\
UÁQUIRI - PPGGEO, v. 2, n. 1, p. 59 - 79, ano 2020 & \\
\hline
\end{tabular}

\title{
ASPECTOS MORFOLÓGICOS DO PARQUE NATURAL MUNICIPAL SERRA DOS PARECIS - MUNICÍPIO DE GUAJARÁ-MIRIM/RO
}

\author{
Juliana Santiago Souza ${ }^{*}$, Dr. Waldemir Lima dos Santos ${ }^{2}$ \\ ORCID: https://orcid.org/0000-0001-8545-738; https://orcid.org/0000-0002-5306-5612
}

${ }^{1}$ Bacharel em Geografia pela Universidade Federal do Acre, Centro de Filosofia e Ciências Humanas, Rio
Branco, Acre, Brasil. *juliana.santiago10@hotmail.com.
${ }^{2}$ Professor da Universidade Federal do Acre, Programa de Pós-graduação em Geografia, Rio Branco, Acre,
Brasil.

Recebido em: 25/03/2020. Aceito em: 06/05/2020. Publicado em: 22/06/2020

DOI:

\begin{abstract}
RESUMO
O presente artigo tem como objetivo fazer uma análise sobre os aspectos geomorfológicos do Parque Natural Municipal Serra dos Parecis, localizado no município de Guajará-Mirim/RO, cujo residual leva o nome local de 'Serra dos Pacaás Novos" que é uma área de preservação permanente, comumente utilizado como ponto turístico. Para isto, foram utilizados métodos de análise de amostras de sedimentos superficiais em laboratório e coleta de dados secundários, com o intuito de compreender os aspectos morfoestruturais da Serra e seu entorno. Foi possível inferir que a morfologia do Parque pode ser resultado do conjunto de agentes intemperizadores que proporcionam o recuo de vertente e os depósitos aluviais superficiais do rio Mamoré.
\end{abstract}

Palavras-chave: Morfoestrutura; Processos geomorfológicos; Parque Natural Municipal Serra dos Parecis.

\section{MORPHOLOGICAL ASPECTS OF THE SERRA DOS PARECIS MUNICIPAL NATURAL PARK - MUNICIPALITY OF GUAJARÁ-MIRIM / RO}

\begin{abstract}
This article aims to make an analysis on the geomorphological aspects of the Serra dos Parecis Municipal Natural Park, located in the municipality of Guajará-Mirim / RO, whose residual takes the local name of 'Serra dos Pacaás Novos" which is a preservation area permanent, commonly used as a tourist spot. For this, methods of analyzing sediment samples in the laboratory and collecting secondary data were used, to understand the morphostructural aspects of the Serra and its surroundings. It was possible to infer that the Park's morphology may be the result of a set of weathering agents that provide the slope retreat and the superficial alluvial deposits of the Mamoré River.
\end{abstract}

Keywords: Morphostructure; Geomorphological processes; Serra dos Parecis Municipal Natural Park. 


\section{ASPECTOS MORFOLÓGICOS DEL PARQUE NATURAL MUNICIPAL SERRA DOS PARECIS - MUNICIPIO DE GUAJARA-MIRIM / RO}

\section{RESUMEN}

Este artículo tiene como objetivo hacer un análisis de los aspectos geomorfológicos del Parque Natural Municipal Serra dos Parecis, ubicado en el municipio de Guajará-Mirim / RO, cuyo residual toma el nombre local de 'Serra dos Pacaás Novos', que es un área de conservación permanente, comúnmente utilizado como lugar turístico. Para esto, se utilizaron métodos de análisis de muestras de sedimentos superficiales en el laboratorio y la recopilación de datos secundarios, para comprender los aspectos morfoestructurales de la Serra y sus entornos. Fue posible inferir que la morfología del Parque puede ser el resultado de un conjunto de agentes meteorizadores que proporcionan la retirada de la vertiente y los depósitos aluviales superficiales del río Mamoré.

Palabras clave: Morfoestrutura; Procesos geomorfológicos; Parque Natural Municipal Serra dos Parecis.

\section{INTRODUÇÃO}

A geomorfologia é uma ciência que tem como principal foco, o estudo das paisagens, formas do relevo terrestre, sua gênese, composição e seus mecanismos, que são entendidos como sistemas históricos, que guardam informações de diversas eras (CHRISTOFOLETTI, 1980; GUERRA; CUNHA, 1994).

Sendo assim, torna-se uma ciência de extrema importância para obtenção de conhecimentos das paisagens e sua gênese. Assim como a paisagem, a geomorfologia também é uma ciência que está em constante processo de renovação, sempre evoluindo e procurando desvendar os fenômenos naturais.

Dentro dessa mesma concepção muitos autores brasileiros desenvolveram estudos geomorfológicos, como Aroldo de Azevedo (1940) que classificou as planícies e planaltos do Brasil. Aziz Ab'Saber (1962) impulsionou os estudos de classificação dos relevos brasileiros, assim como Jurandyr Ross (1989) que estendeu esse estudo, tornando-o mais detalhado, no qual pela primeira vez, foi considerada a existência de depressões, divididas em 28 unidades de relevo e que é usado até os dias de hoje como referencial teórico.

Portanto, a realização dessa pesquisa, busca elucidar as características morfoestruturais do relevo residual da Serra dos Parecis, localizado no município de Guajará Mirim/RO, assim como os processos e fenômenos que determinaram a morfogênese da área de estudo; analisar o relevo, tentando desvendar os processos endógenos e exógenos que ali ocorrem, e que ao longo do tempo deram origem ao modelado que reside hoje e que ainda está em contínua mudança. 


\section{MATERIAL E MÉTODOS}

A presente pesquisa foi realizada em 5 (cinco) etapas, sendo a primeira, a realização de um banco de dados bibliográfico e cartográfico do local a ser estudado. A segunda etapa deuse mediante visitas in loco, onde foram realizadas coletas e análises de geocoberturas, relevo, flora e fauna.

Para tal coleta foram abertos 5 (cinco) pontos de prospecção ao redor do Parque para analisar o perfil do mesmo, a fim de obter melhor compreensão dos materiais que compõem o entorno da Serra.

$\mathrm{Na}$ terceira etapa foram realizadas as análises de 15 (quinze) amostras de materiais da área de estudo, no laboratório de Geomorfologia e Sedimentologia da Universidade Federal do Acre.

$\mathrm{Na}$ quarta etapa da pesquisa, realizou-se a elaboração de análises granulométricas no tocante aos tamanhos areia, silte e argila de cada ponto coletado, conforme método da EMBRAPA (1997).

$\mathrm{Na}$ quinta etapa da pesquisa, foi realizada a elaboração do material cartográfico e gráfico, que foi feita por meio dos produtos de Sensoriamento Remoto, onde foram confeccionados os mapas de localização e delimitação de área de estudo sedimentológico, geomorfológico e hipsométrico, utilizando-se do software QGIS 3.8.1 (Zanzibar) e o Excel 2010.

\subsection{Descrição da área de estudo}

O Parque Natural Municipal Serra dos Parecis, objeto de estudo dessa pesquisa, localiza-se no município de Guajará-Mirim, no oeste do estado de Rondônia, nas coordenadas de $65^{\circ}$ e $65^{\circ} 30^{\prime} \mathrm{W}$ e $10^{\circ} 30^{\prime}$ e $12^{\circ} 30^{\prime} \mathrm{S}$. Está situado entre o município de Nova Mamoré e Campo Novo de Rondônia, e a nordeste com o município de Governador Jorge Teixeira (Fig. 1). Seu principal ponto de acesso se dá pela BR-425. 
Figura 1: Mapa de localização da área de estudo (2019).

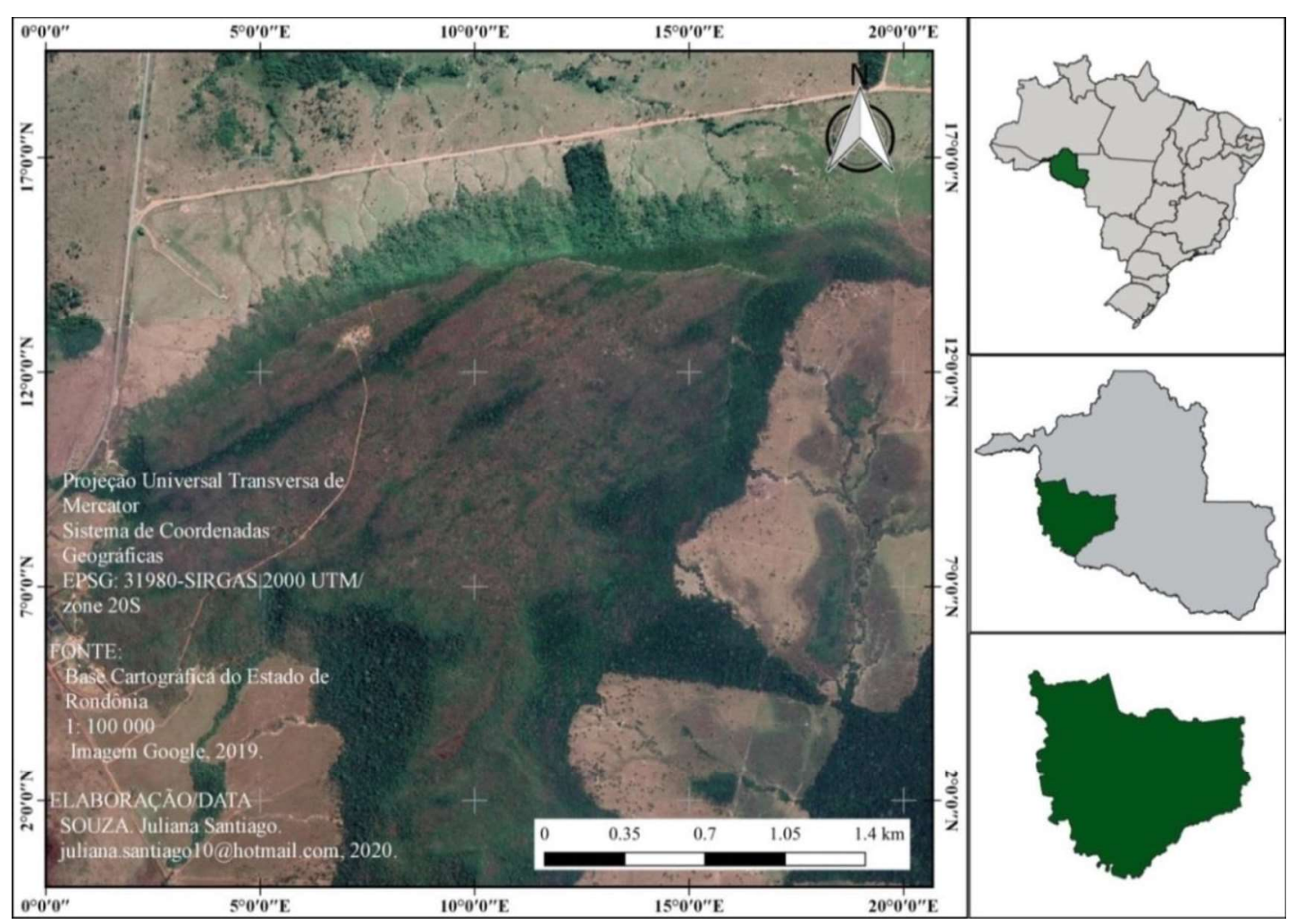

\subsection{Aspectos Naturais}

Segundo a ficha técnica de unidade de conservação do Plano de Manejo do Parque (2009), ele se apresenta como Bioma Amazônico, com predomínio de Floresta Ombrófila Densa e Aberta, que são locais que eram denominados florestas pluviais, mas que atualmente possuem solo mais seco.

A área de estudo possui uma vegetação bem diversificada, predominante do tipo savana florestada, floresta equatorial e floresta de transição, que é nada mais que vegetação herbácea, com predomínio em gramíneas, com a presença de extratos arbóreos e arbustivos bem espaçados entre si.

Possui vastas áreas ao derredor do Parque constituídas de atividades de pecuária (pastagens) (Fig. 2), enquanto se observa as áreas de Savana Florestada ou Floresta Densa, na medida em que as cotas altimétricas aumentam. 
Figura 2: Mapa de vegetação do Parque Natural Municipal Serra dos Parecis (2019).

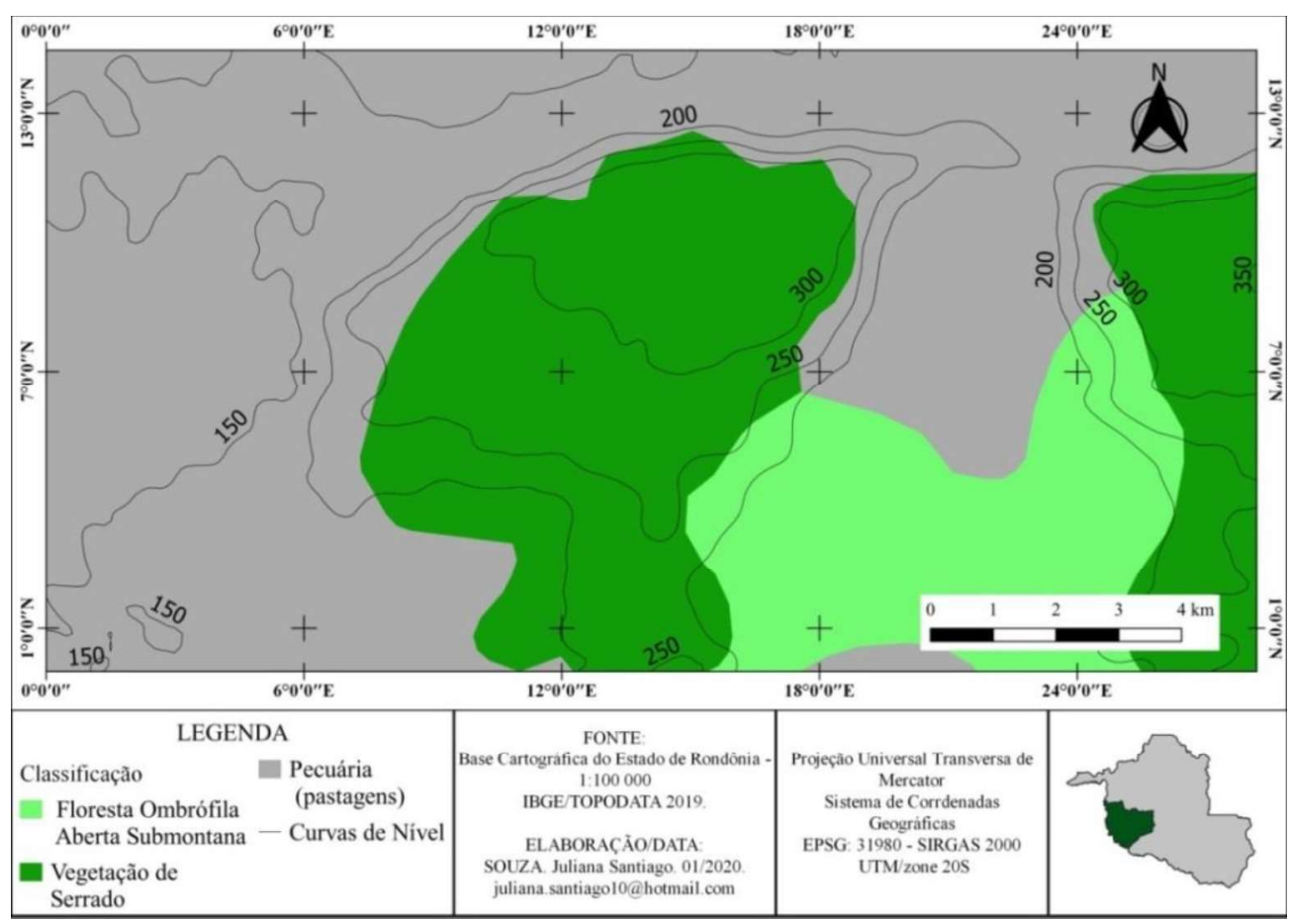

\subsection{Hidrografia}

Quanto à rede hidrográfica da área de estudo, destaca-se o rio Mamoré, como o principal corpo hídrico, se apresentando como principal obstáculo de intercâmbio entre brasileiros e bolivianos e mostrando-se como divisa natural entre os dois países.

Originado na Cordilheira dos Andes, é denominado de Grande de La Plata, vindo a se tornar rio Mamoré somente quando alcança a região de Guajará-Mirim. Posteriormente, quando se encontra com o rio Beni, juntos, tornam-se o rio Madeira. Ele faz parte da Bacia Amazônica e durante todo o seu percurso corre em direção norte, sendo sua maior parte em território boliviano. Seus principais afluentes são os rios: Guaporé, Lajes e Pacaás Novos.

\subsection{Cobertura Pedológica}

Segundo o mapa de solos do IBGE (2006), pode-se concluir que o solo predominante em Guajará-Mirim caracteriza-se como Neossolo Flúvico Tb Distrófico + Gleissolo Háplico Tb Distrófico + Gleissolo Háplico Tb Eutrófico, ambos os solos minerais, que apresentam saturação de água, são sedimentos recentes e que estão presentes em várzeas e planícies e fazem 
parte da região de depressão em torno da Serra. Também foi possível notar que há afloramento de rochas + Neossolo Litólico Distrófico típico (NLdt), com textura arenosa, relevo forte ondulado são solos geralmente rasos e com relevos declivosos, que podem ser encontrados na área de depressão ao redor da Serra e na mesma.

Há presença de Latossolo vermelho Distrófico $(\mathrm{LVd})$ que possui uma textura mais argilosa, com relevo plano + Latossolo Vermelho-Amarelo Distrófico (LVAd), que apresenta textura argilosa, com um relevo mais plano e suave ondulado, também localizado na área de depressão ao redor da Serra (IBGE, 2006).

Como se observa na Fig. 3, a área possui presença de Neossolo Quartzarênico Órtico (RQo), que são solos originados de depósitos arenosos, que geralmente possui um relevo plano ou suave ondulado, juntamente com o Argissolo Amarelo (AA), que geralmente são originados de rochas cristalinas ou sedimentos do Grupo Barreiras, possui textura arenosa com relevo plano, e juntamente com o Neossolo Litólico Distrófico (NLd) formam a região de depressão em torno da Serra.

Verifica-se também, segundo a Figura 3, que há ocorrência de afloramentos rochosos (AR) na parte mais alta do Parque variando entre $175 \mathrm{~m}$ e $325 \mathrm{~m}$.

Figura 3: Mapa de solos do Parque Natural Municipal Serra dos Parecis (2019).

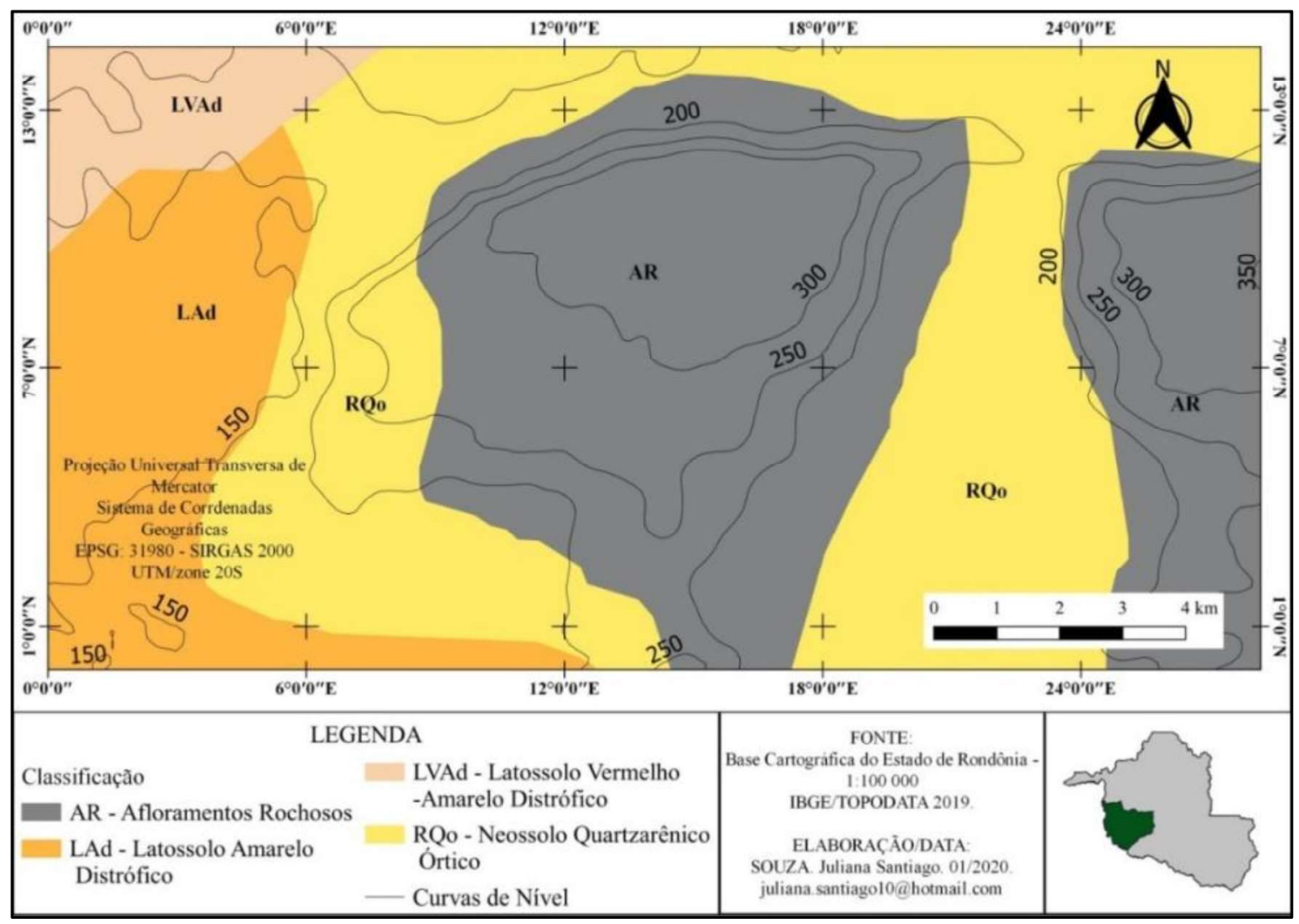




\subsection{Contexto Geomorfológico}

O Parque Natural Municipal Serra dos Parecis, é constituído de três (3) tipos de relevo: os planaltos residuais Sul-Amazônico, a depressão da Amazônia ocidental e a depressão marginal Sul-Amazônica.

Os planaltos residuais Sul-Amazônico são áreas onde residem rochas sedimentares e cristalinas, que se estendem ao Sul do Rio Amazonas, vindo do Pará até Rondônia. A depressão da Amazônia ocidental é uma vasta área que tem origem sedimentar no Oeste da Amazônia, que tem a altitude em torno de 200m, com uma superfície aplainada (ROSS, 2005).

Já a depressão marginal Sul-amazônica, é composta por rochas sedimentares com altitudes que variam entre $100 \mathrm{~m}$ e $400 \mathrm{~m}$ que se localiza na porção Meridional da Amazônia e se intercala com os planaltos residuais Sul-Amazônico (ROSS, 2005).

O Parque é dividido em duas estruturas com datações diferenciadas, sendo a parte de cima (o topo) do período cretáceo, referente ao último período da Era Mesozoica, que durou de 135 a 65 milhões de anos (Fig. 4). E na estrutura da parte de baixo (o sopé) é referente ao período Proterozóico superior, que supostamente pode ter sido originado por compressões de origem continental, consequentemente, afetando grande parte das litologias que surgiram em outros períodos (ROSS, 2005).

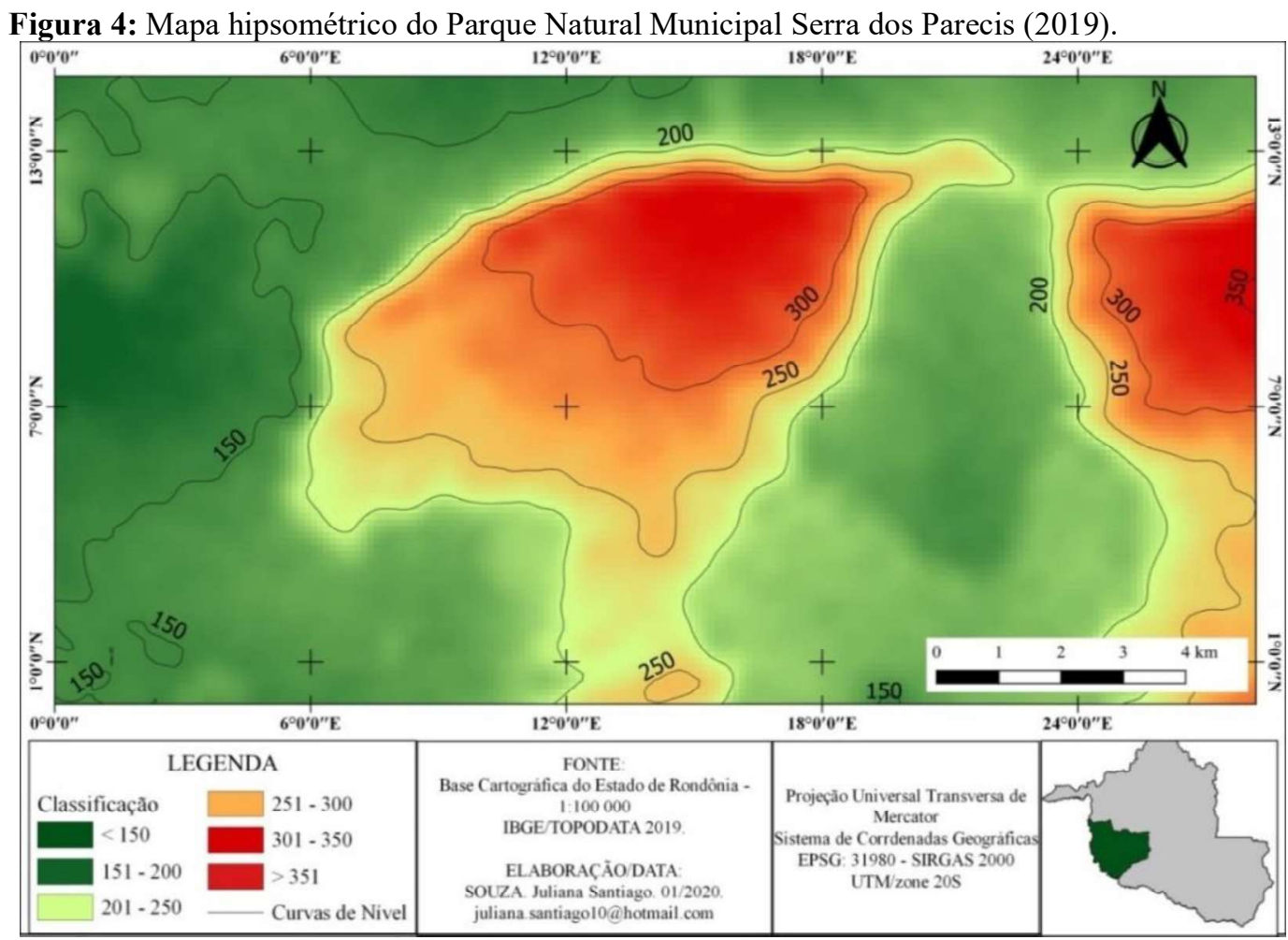


A região de Guajará-Mirim, onde se localiza o parque, encontra-se em sua estrutura, 96\% num tabuleiro terciário entre a altitude de 100 a 150m de altitude em relação ao nível do mar, $2 \%$ está acima, entre 100 e $200 \mathrm{~m}$, e $2 \%$ acima de $200 \mathrm{~m}$.

O estudo permitiu observar que no topo, com quase $300 \mathrm{~m}$ de altitude (Fig. 4), existem afloramentos rochosos, indicando que as rochas não foram trazidas, mas foram originadas no local pelo fenômeno que chamamos de afloramentos halogenéticos.

\section{RESULTADOS E DISCUSSÃO}

\subsection{Fatores Intemperizadores do Parque Natural Municipal Serra dos Parecis/Ro}

Intemperismos são o conjunto de processos que podem ser mecânicos ou físicos, químicos e biológicos que, dependendo da sua intensidade, pode decompor ou desintegrar as rochas (PENTEADO, 1978; TORRES et al, 2013).

Essa intemperização ou meteoriação da rocha se torna um dos fatores responsáveis pela modelagem da paisagem na área de estudo, possuindo uma extensão significativa de afloramentos rochosos, que em grande parte impedem que a vegetação cresça, deixando-a propensa a intemperismos físicos e químicos e consequentes processos erosivos.

Cita-se primeiramente, um dos fatores de extrema importância na esculturação da dinâmica do Parque, chamados de lagos periódicos, que ocorrem nos períodos chuvosos que vão de setembro a maio, formados pelo acúmulo das águas da chuva ao longo do percurso do Parque. Por meio deste, ocorre também às decomposições químicas e desagregações mecânicas.

A decomposição química ocorre através das chamadas marmitas (Fig. 5), que são cavidades que aparecem nas rochas por meio do turbilhonamento das águas. Essas águas formam cavidades, diluindo a superfície das rochas, ou produzindo atritos de seixos (CHRISTOFOLETTI, 1980). No parque Serra dos Parecis, é muito comum encontrar esse fenômeno, principalmente durante épocas chuvosas. 
Figura 5: Marmitas, decorrente da decomposição química na Serra (2017).

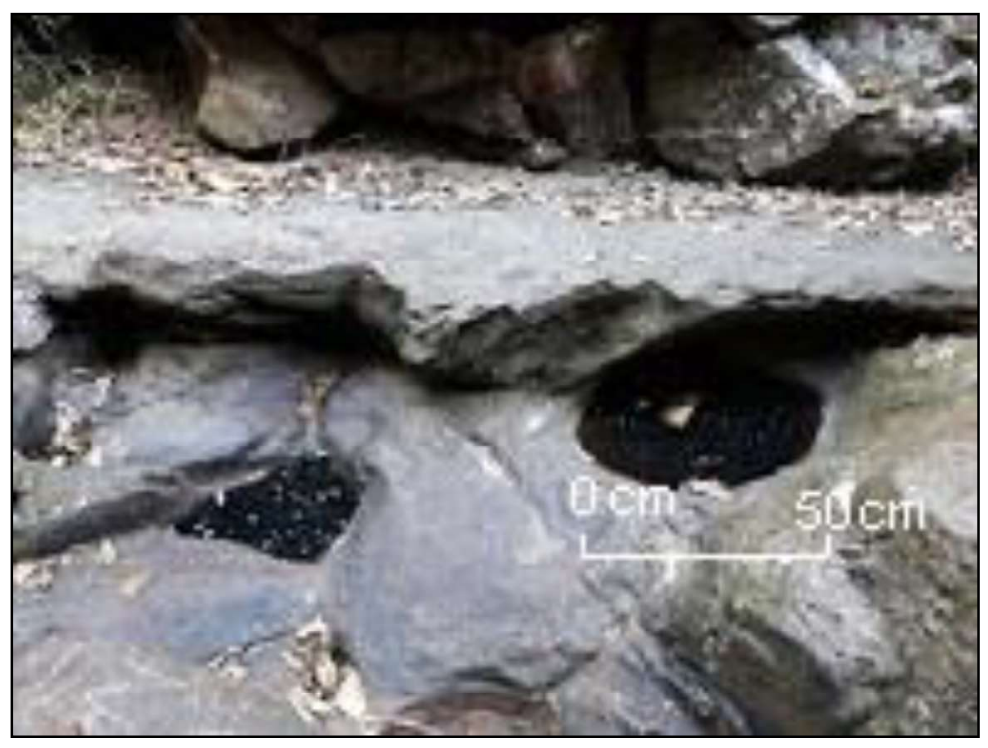

Outro processo de intemperismo químico se dá pela oxidação, que ocorre quando a água infiltra na rocha reagindo com os minerais da mesma, oxidando e formando rachaduras na superfície (GUERRA; CUNHA, 1994; PRESS et al, 2006). Quando a rocha oxida, perde suas propriedades minerais e apresentam aparências de ferrugem (Fig. 6).

Figura 6: Intemperismo químico na Serra (2018).

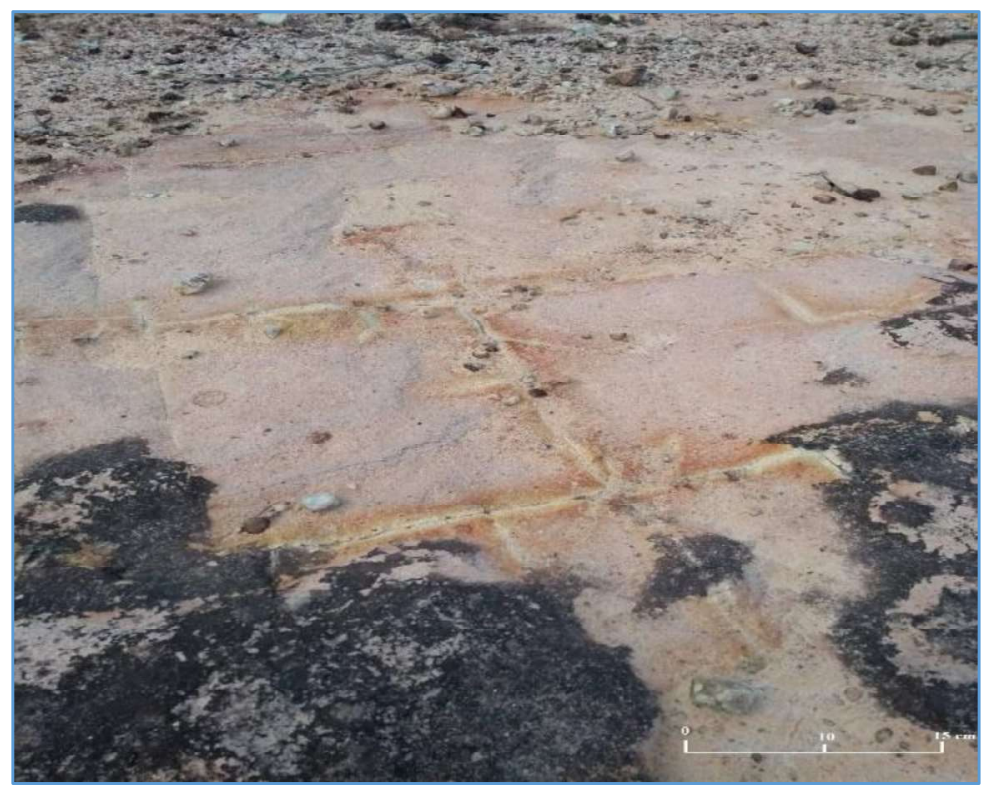

A desagregação mecânica ou física é o desacoplamento ou quebramento das rochas maciças, por meio de fatores endógenos e exógenos, como a variação de temperatura, agentes pluviais, eólicos e biológicos. Além da movimentação tectônica, que pode ocasionar tanto o rolamento das rochas, como cisalhamentos nas mesmas (CHRISTOFOLETTI, 1980; TEIXEIRA et al, 2000). 
Os cisalhamentos ou falhas são a fraturação ou desnivelamento das rochas, por meio de movimentos tectônicos, o que contribui no modelado do Parque e produz uma paisagem diferenciada. Todos esses aspectos podem ser claramente observados no Parque Natural Municipal Serra dos Parecis.

Observou-se, ainda, a ocorrência de intemperismo químico-biológico, através da presença de musgos sobre as rochas. Esse tipo de intemperismo ocorre por causa de musgos, liquens e algas possuírem em sua composição $\mathrm{CO}_{2}$, nitratos e ácidos orgânicos que, quando em contato com a rocha/solo, desencadeiam uma reação química de intemperização na mesma (PENTEADO, 1978; TORRES et al, 2013).

\subsection{Influência do rio Mamoré na modelagem do Parque Natural Municipal Serra dos Parecis}

Nessa etapa aborda-se algumas características geológicas, geomorfológicas e pedológicas do rio Mamoré, que de alguma forma podem se correlacionar a modelagem do Parque Natural Municipal Serra dos Parecis.

Como se observa na Figura 7, o solo que se apresenta as margens e ao derredor do rio Mamoré, é do tipo Neossolo Flúvico Tb Distrófico (RYbd), comumente encontrado em margens de rios e áreas de drenagem que possuem relevo plano. São solos que variam de baixa à média porcentagem de argila e baixa fertilidade.

Ao seu derredor, possui solos do tipo Latossolo Amarelo Distrófico (LAdl) sendo argilosos e classificados como solos profundos. São bem estruturados e possuem uma boa drenagem. Geralmente as áreas que possuem este solo, são áreas que tem muita intervenção humana, e o mesmo apresenta-se bastante modificado, por ser utilizado em maior escala na prática da agricultura e pastagem.

Quanto à sua formação geológica, suas margens e derredor, possuem uma cobertura detrito-laterítica neo-pleistocênica, que é similar a Pleistocênica, composta de sedimentos argilosos, caolíniticos, alóctones e autóctones, no entanto, se difere por ter sido formado por lateritas imaturas, possuindo alto teor de ferro (IBGE, 2006). 
Figura 7: Mapa de solos da área ao redor do Rio Mamoré (2019).

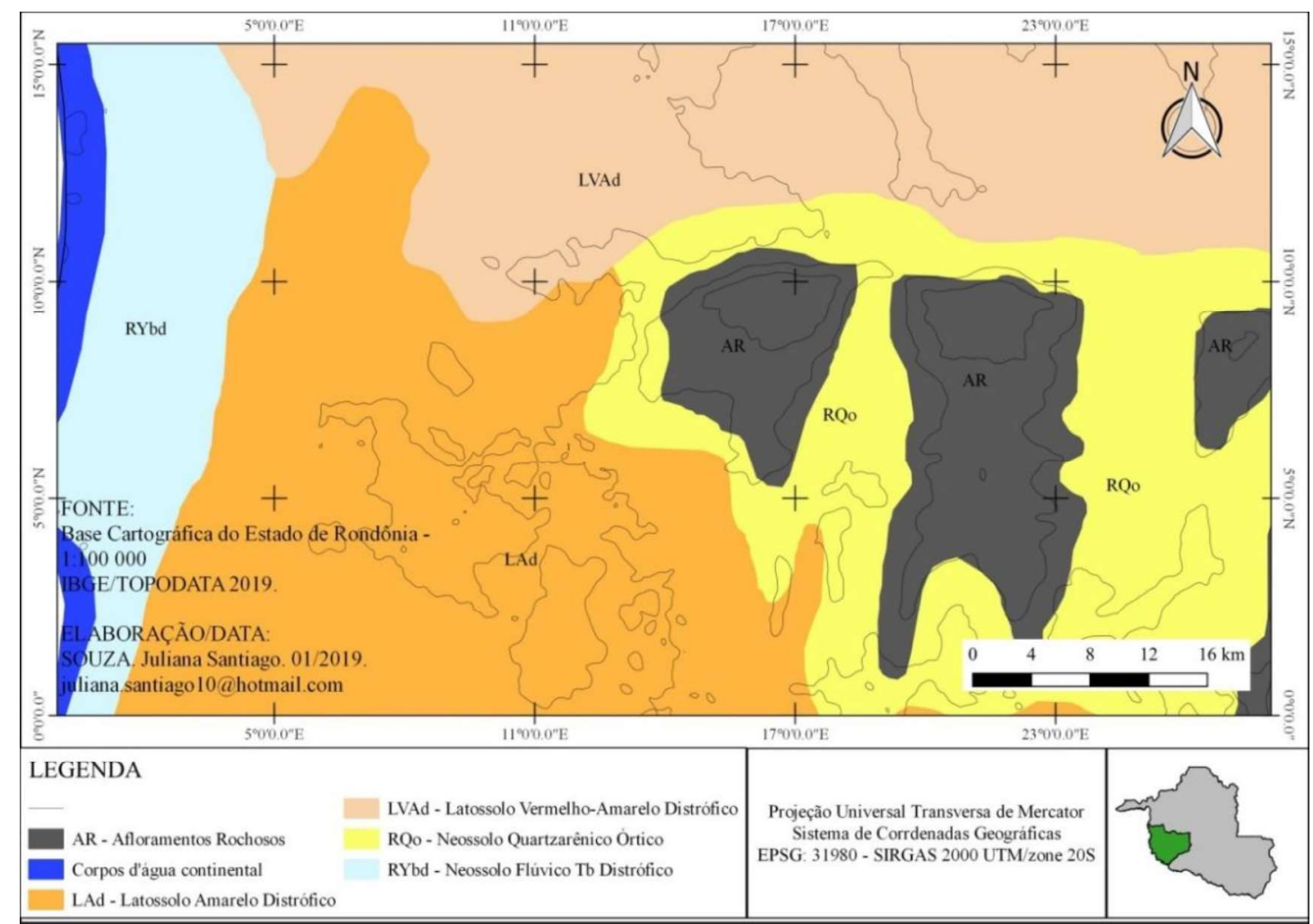

Foram observados também, depósitos aluvionares holocênicos ao longo do percurso, que são depósitos constituintes de areias grossas e conglomeráticas, representando, residuais de canal; possui pelíticos, que são rochas criptoclásticas formados por materiais finos e consolidados, e se apresentam em áreas de transbordamento (IBGE, 2006).

Possui formação Ji-Paraná, que tem datação do Calimiano entre $1600 \mathrm{Ma}-1400 \mathrm{Ma}$, segundo o mapa geológico do IBGE (2006), esse complexo é composto de: "ortgnaisses de composição granítica-granodiortica a tonalitica migmatizados e granitoides. Raros granulitos e raras supracrustais como quartzitos, xistos e anfibolitos".

Constitui-se, também, de sedimentos da formação Palmeiral, que se apresenta como um extenso sistema fluvial que está relacionado a um regime distensivo, que afetou a borda do Craton Amazônico. Segundo o mapa geológico do IBGE (2006) o mesmo é composto de paraconglomerados e ortoconglomerados, arenitos ortoquartizitos e feldspático juntamente com horizontes compostos por tufacéos, quartzitos e argilitos.

Em seu relevo é possível observar dois tipos de modelagens: a modelagem de acumulação que é representado pela Planície Amazônica que é composta por depósitos sedimentares do período Quaternário, composta por sedimentos de origem aluvionar, e caracterizada por ser uma planície de inundação Holocênica. 
E a modelagem de dissecação, que é representado pela Depressão do Madeira - Ji Paraná (Fig. 8), é datada do Neoproterozóico, constituída de ilhas rochosas de tamanhos e aspectos variados, possuindo afloramentos de rochas em toda a área.

As características de um rio guardam relação direta com a formação e as características nos lugares que estão ao seu redor, influenciando a paisagem do local. Por meio de visitas in loco, verificou-se que tais características podem ter relação com o rio Mamoré.

Umas das primeiras observações, é que as espécies vegetais, encontradas perto do rio, assemelham-se com as que se encontra ao redor do Parque, o que pode indicar que a geocobertura pode conter as mesmas composições minerais. Das observações, destaca-se que as espécies vegetais encontradas perto do rio se assemelham com aquelas encontradas ao redor do Parque. Esta verificação revela indicativo de que a cobertura pode conter as mesmas composições minerais.

Outra observação é com relação ao solo, com indicativo de ser bastante argiloso e arenoso. Isso é típico de lugares onde se encontram cursos d'águas e revela indícios de que o rio Mamoré, em algum momento de sua formação pode ter residido no local onde se localiza a serra ou no seu derredor. Esse comportamento é comum para rios em formação, cujo curso deve mudar de direção até se estabelecer em local específico.

\subsection{Características geológicas e morfológicas do Parque Natural Municipal Serra dos Parecis}

No contexto geológico da área de estudo, foi possível classificar a litologia do Parque Natural Municipal Serra dos Parecis como Planalto Residual do Madeira - Roosevelt, que faz parte do domínio morfoestrutural dos Crátons Neoproterozóicos (Fig. 8).

Essa formação é constituída de rochas vulcânicas feldspáticas e é caracterizada por apresentar relevo pediplanado desnudado, que se constitui numa superfície de aplainamento, onde se mostra relativamente conservada, mas que perdeu sua continuidade, em consequência da mudança dos sistemas morfogenéticos.

Comumente apresenta-se dissecada e separada por escarpas, rampas que aparecem nas bordas das serras, e ressaltos advindo de outros modelados de aplainamento e dissecação relacionada à sistemas morfogenéticos. Apresenta-se desnudada em consequência da retirada de camada sedimentar, por meio dos intemperismos. 
Figura 8: Mapa Geológico do Parque Natural Municipal Serra dos Parecis (2019).

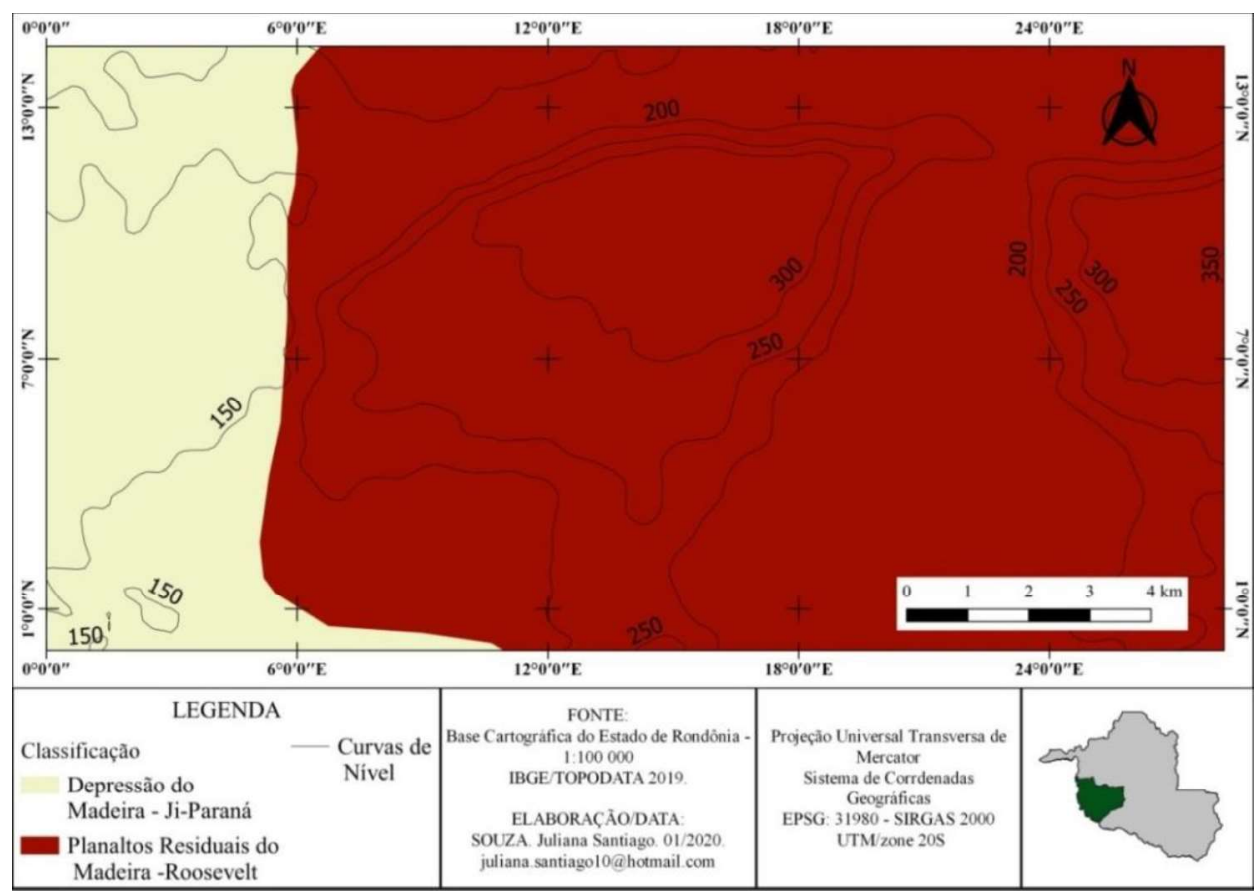

Segundo Latrubesse (1996) o mesmo possui relevo tabular de clima tropical, ou seja, possui topo levemente retilíneo pediplanizado com superfícies inclinadas, formadas pela coalescência de pedimentos e apresenta-se bastante dissecada nas bordas. Seu topo se apresenta em estado de erosão avançado, apresentando grandes blocos de rochas soltas, que tiveram origem devido aos intemperismos.

O parque apresenta em seu perfil, uma estreita faixa escarpada entre o topo e o pedimento, que pode ter sido originada por meio de erosão linear, escavados por agentes erosivos, por meio de escoamento e infiltração da água das chuvas ou por meio de forças endógenas produzidas por abalos tectônicos.

\subsection{Análise de solo do Parque Natural Municipal Serra dos Parecis}

Para melhor análise e compreensão acerca do solo e relevo dessa área de pesquisa, foi necessário realizar algumas observações quanto à granulometria do solo e, por esse motivo, foram realizadas visitas in loco para aberturas de trincheiras e coleta de elementos amostrais.

Para isso foram escolhidos 5 (cinco) pontos de coleta, sendo 4 (quatro) ao redor do Parque Natural, e 1 (um) localizado dentro do mesmo, foram feitas coletas que variam de 0 $48 \mathrm{~cm}, 0-50 \mathrm{~cm}, 0-60 \mathrm{~cm}, 0-50 \mathrm{~cm}$ e $0-70 \mathrm{~cm}$. Devido ao solo ser composto de várias 
camadas rochosas, não foi possível fazer uma coleta padronizada, uma vez que foi cavado até onde o solo permitiu.

O primeiro ponto onde foi feito a coleta de solo, se encontra no sopé do Parque, dentro de uma das propriedades privadas que circunda o mesmo (fazenda), nas coordenadas $\mathrm{O}$ 65'16'14,9"; S 1043'10,0"que tem o principal foco no uso do solo, o pastoreio de gado (ver mapa 9). A esse ponto pôde-se fazer várias observações, quanto ao perfil da área, como, a cobertura vegetal, que é uma vegetação rasteira característica de pasto, portanto não é uma vegetação primária.

Quanto ao terreno, verificou-se alto nível de pedregosidade, devido às rochas que rolam do Parque e o nível de erosão, que por ser uma área que se encontra abaixo do Parque, recebe toda a água que desce da mesma lavando o solo, refletindo em um alto grau de intemperismo, podendo classificar a área com uma drenagem de média a alta.

Quanto á rochosidade, que se refere à exposição de rochas do embasamento, na superfície, é possível classificar como alta, uma vez que foi muito comum presenciar esse fenômeno na paisagem. O relevo pode ser classificado de medianamente acentuado.

Figura 9: Mapa de pontos (2019).

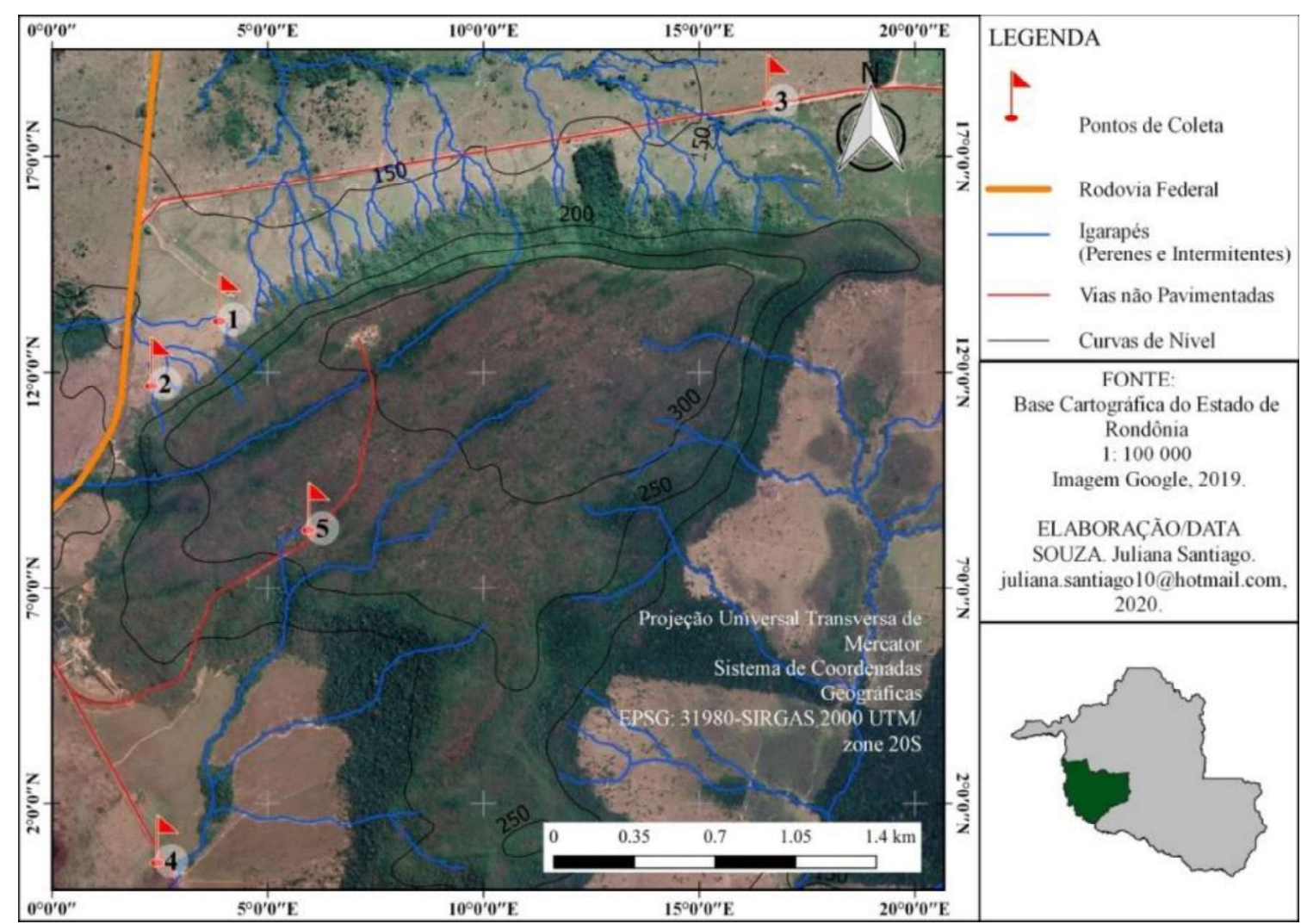


Nesse ponto o modelo da trincheira se estruturou da seguinte forma: camada (1) foi de 0 - 40cm; e a camada (2) de 40 - 50cm, não foi possível coletar uma terceira camada, pois foi encontrado, a camada rochosa a partir dos $50 \mathrm{~cm}$.

Com isso, realizou-se análise mais detalhada no laboratório, estudando a granulometria por meio da separação da areia, argila e do silte. O processo permitiu determinar a porcentagem que cada elemento tem na formação dessa granulometria (tab. 1).

Tabela 1: Características da granulometria do ponto (1)

\begin{tabular}{ccccc}
\hline AMOSTRA & AREIA GROSSA & $\begin{array}{c}\text { AREIA } \\
\text { FINA }\end{array}$ & ARGILA & SILTE \\
\hline $\mathrm{P} 1-\mathrm{C} 1: 0-40 \mathrm{~cm}$ & $72 \%$ & $45 \%$ & $18 \%$ & $10 \%$ \\
$\mathrm{P} 1-\mathrm{C} 2: 40-50 \mathrm{~cm}$ & $71 \%$ & $45 \%$ & $18 \%$ & $11 \%$ \\
\hline
\end{tabular}

Por meio dessa análise, foi possível observar que nesse ponto, em torno de $143 \%$ do solo é composto de areia, seja ela grossa ou fina, $36 \%$ é composto por argila e apenas $21 \%$ de silte, ou seja, é um perfil mais arenoso, como mostra no gráfico dos pontos (Fig. 10), cuja classificação é franco-arenoso, por meio do triângulo textural.

Solos classificados como francos, são definidos assim por terem em sua composição uma proporção relativamente igual de areia, silte e argila, embora não signifique que os 3 (três) tamanhos tenham quantidades exatamente iguais. A granulometria com franco arenoso é, a que apresenta em sua estrutura, uma quantidade maior de areia, deixando-o com uma textura moderadamente grosseira e de fácil drenagem.

Figura 10: Granulometria das geocoberturas, por ponto de coleta.

\begin{tabular}{|c|c|c|c|c|c|c|c|c|c|c|c|c|c|c|c|c|}
\hline $\begin{array}{l}80 \% \\
70 \%\end{array}$ & & & & & & & & & & & & & & & & \\
\hline $60 \%$ & & & & & & & & & & & & & & & & \\
\hline $50 \%$ & & & & & & & & & 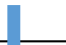 & & & & & & & \\
\hline $40 \%$ & & & & & & & & & & & & & & & & \\
\hline $30 \%$ & & & & & & & & & & & & & & & & AREIA GROSSA \\
\hline $20 \%$ & & & & & & & - & _ & 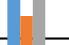 & & & _. & & & & AREIA FINA \\
\hline $10 \%$ & & & & & & & & & & & & & & & L & ARGILA \\
\hline $0 \%$ & & & & & & & & & & & & & & & & SILTE \\
\hline & $0-$ & $40-$ & $0-$ & $20-$ & $50-$ & $0-$ & $30-$ & $40-$ & $0-$ & $30-$ & $50-$ & $0-$ & $20-$ & $40-$ & $45-$ & \\
\hline & 40 & 50 & 20 & 50 & 70 & 30 & 40 & 50 & 30 & 50 & 60 & 20 & 40 & 45 & 48 & \\
\hline & P1- & P1- & P2- & P2- & P2 - & P3- & P3- & P3- & P4- & P4- & P4- & P5- & P5- & P5- & P5- & \\
\hline & $\mathrm{C} 1$ & $\mathrm{C} 2$ & $\mathrm{C} 1$ & $\mathrm{C} 2$ & C3 & C1 & $\mathrm{C} 2$ & C3 & $\mathrm{C} 1$ & $\mathrm{C} 2$ & C3 & C1 & $\mathrm{C} 2$ & C3 & C4 & \\
\hline
\end{tabular}


O segundo ponto localiza-se dentro da mesma propriedade, nas coordenadas $65^{\circ} 16$ '24.4” W; $10^{\circ} 43^{\prime} 19.0$ ' S. A amostra foi tirada de um ponto igualmente ao sopé do Parque, seu perfil ficou estruturado em: camada (1), de $0-20 \mathrm{~cm}$; camada (2), de $20-50 \mathrm{~cm}$; camada (3) de $50-70 \mathrm{~cm}$, sendo este um dos pontos, onde foi possível fazer uma coleta mais profunda (tab. 2).

Foi possível observar uma vegetação rasteira de pasto, terreno pedregoso e com uma drenagem de média à alta, semelhante ao ponto (1). Com relação ao rochosidade, também foi possível observar na paisagem, quanto à declividade, medianamente acentuado.

Tabela 2: Características da granulometria do ponto (2)

\begin{tabular}{ccccc}
\hline AMOSTRA & $\begin{array}{c}\text { AREIA } \\
\text { GROSSA }\end{array}$ & AREIA FINA & ARGILA & SILTE \\
\hline P2-C1: $0-20 \mathrm{~cm}$ & $73 \%$ & $43 \%$ & $18 \%$ & $09 \%$ \\
P2-C2: $20-50 \mathrm{~cm}$ & $71 \%$ & $42 \%$ & $19 \%$ & $10 \%$ \\
P2-C3: $50-70 \mathrm{~cm}$ & $71 \%$ & $43 \%$ & $20 \%$ & $09 \%$ \\
\hline
\end{tabular}

Através da análise, foi possível observar que $215 \%$ do solo é composto de areia, seja ela grossa ou fina; $57 \%$ ou mais de argila e apenas $28 \%$ ou menos de silte. Se comparado com o ponto anterior (ponto 1), a diferença é apenas de algumas poucas gramas (ver Figura 10).

Segundo o triângulo textural, as camadas (1) e (2) foram classificadas como franco arenosas, e a camada (3) possui textura franco argilosa arenosa. As granulometrias classificadas como franco argiloso arenoso, possui em sua estrutura, a argila e a areia, como componentes mais predominantes, no entanto, com os níveis de argila mais altos, possuem uma textura moderadamente fina.

O terceiro ponto, também localizado na mesma propriedade, que os pontos (1) e (2), nas coordenadas $\mathrm{O} 65^{\circ} 14^{\prime} 57.9^{\prime \prime}$; S 1042’39.4", o mesmo foi localizado, um pouco mais distante do Parque, no entanto ainda se encontra dentro dos limites da área de pesquisa.

A estrutura do perfil do ponto (3) ficou configurada em: camada (1) de $0-30 \mathrm{~cm}$; camada (2) de 30 -40cm; camada (3) de $40-50 \mathrm{~cm}$, onde foi possível, observar bem a diferença entre os perfis (tab. 3). A cobertura vegetal presente é rasteira, característica de pasto, sendo possível notar que mesmo um pouco longe, pode-se encontrar bastante seixo rolado do Parque, e menos 
rochosidade, relevo menos acentuado, ainda bem intemperizado, onde é possível até ser encontrado voçorocas.

Tabela 3: Características da granulometria do ponto (3)

\begin{tabular}{ccccc}
\hline AMOSTRA & AREIA GROSSA & AREIA FINA & ARGILA & SILTE \\
\hline P3-C1: 0-30cm & $62 \%$ & $15 \%$ & $30 \%$ & $08 \%$ \\
P3-C2: 30-40cm & $61 \%$ & $16 \%$ & $28 \%$ & $11 \%$ \\
P3-C3: $40-50 \mathrm{~cm}$ & $66 \%$ & $14 \%$ & $27 \%$ & $07 \%$ \\
\hline
\end{tabular}

Por meio da análise foi possível observar que nesse ponto (3), em torno de $189 \%$ do solo é composto de areia, seja ela grossa ou fina; $85 \%$ de argila e apenas $26 \%$ de silte. Se comparado com os pontos anteriores, já é possível notar a diferença nas gramas de areia, que se apresenta em quantidade inferior, e a da argila que se apresentou em quantidades maiores (Fig. 10). Foi classificado como solo franco-argilo-arenoso em suas 3 (três) camadas.

O quarto ponto, situado nas coordenadas $\mathrm{O} 65^{\circ} 16^{\prime} 14.9^{\prime \prime}$; S 1044'25.5”, esse local, que tem como uso do solo, a criação de cavalos, com vegetação rasteira, ou seja, não é uma vegetação original, pode-se notar um terreno bem pedregoso semelhante aos 3 (três) primeiros pontos, isso se deve ao fato de todos eles circundarem o Parque.

Apresenta em sua paisagem pontos com rochas expostas, um solo bastante erodido, com uma boa drenagem, possui um teor considerável de areia em sua composição, o que permite que o mesmo seja bastante poroso. O perfil teve profundidade de $0-60 \mathrm{~cm}$ (tab. 4 ).

Tabela 4: características da granulometria do ponto (4)

\begin{tabular}{ccccc}
\hline AMOSTRA & AREIA GROSSA & AREIA FINA & ARGILA & SILTE \\
\hline P4-C1: 0-30cm & $58 \%$ & $25 \%$ & $29 \%$ & $13 \%$ \\
P4-C2: 30-50cm & $54 \%$ & $25 \%$ & $01 \%$ & $45 \%$ \\
\hline P4-C3: 50-60cm & $52 \%$ & $23 \%$ & $20 \%$ & $28 \%$ \\
\hline
\end{tabular}


O estudo permitiu observar que nesse ponto os níveis de areia foram diminuindo, apresentando em torno de $164 \%$, seja ela grossa ou fina, $50 \%$ ou mais de argila, e mais de $86 \%$ de silte, exceto na camada 2 (dois), que está bem a baixo (Fig. 10). Nesse ponto é possível notar que o solo já mudou um pouco, para mais argiloso, sendo classificado como franco argiloso arenoso nas camadas (1) e (3), foi onde se apresentou níveis maiores de argila, e a camada (2), como franco arenoso, onde percebemos níveis baixos de argila.

No quinto ponto de coleta, localizado dentro dos limites do Parque Natural Municipal Serra dos Parecis, nas coordenadas $\mathrm{O} 65^{\circ} 16^{\prime} 02.9^{\prime \prime}$; S $10^{\circ} 43^{\prime} 39.3^{\prime \prime}$, próximo à estrada de acesso a Serra. Por se localizar no próprio Parque, não foi possível escavar tanto, devido à camada rochosa estar mais próxima da superfície (tab. 5).

Tabela 5: Características da granulometria do ponto (5)

\begin{tabular}{ccccc}
\hline AMOSTRA & AREIA GROSSA & AREIA FINA & ARGILA & SILTE \\
\hline P5-C1: 0-20cm & $58 \%$ & $27 \%$ & $15 \%$ & $27 \%$ \\
P5-C2: $\mathbf{2 0 - 4 0 c m}$ & $66 \%$ & $29 \%$ & $13 \%$ & $21 \%$ \\
P5-C3: 40-45cm & $68 \%$ & $31 \%$ & $09 \%$ & $17 \%$ \\
\hline P5-C4: 45-48cm & $70 \%$ & $44 \%$ & $13 \%$ & $23 \%$ \\
\hline
\end{tabular}

Por se encontrar dentro dos limites do Parque, que é uma área de preservação, o ponto de coleta não apresenta nenhum tipo de uso, a não ser, o turístico. Sua cobertura vegetal, é aparentemente primaria, sem marcas de desmate, com alta pedregosidade, alta rochosidade, alto grau de intemperismo, terreno bastante acentuado e com níveis altos de drenagem, sendo possível observar pequenos córregos durante o percurso.

Os resultados permitiram concluir que, nesse ponto, os níveis de areia foram bem variados conforme as camadas, apresentando em torno de $262 \%$, seja ela grossa ou fina, $50 \%$ de argila e $88 \%$ de silte (Fig. 10). Observou-se que o solo do Parque, é um pouco diferente do seu derredor. A granulometria desse ponto foi classificada pelo triângulo de textura como franco-arenoso, ou seja, possui níveis mais altos de areia.

Através das análises da granulometria em laboratório, foi possível fazer um comparativo da porcentagem de areia grossa e fina, silte e argila em cada ponto coletado. Verifica-se que 
não houve um padrão na porcentagem de areia (Fig. 10), no entanto, nenhuma foi abaixo de $50 \%$, o que indica que o solo dessa área, é bem arenoso, principalmente, o solo do Parque (Pontos: 1, 2 e 5).

Observou-se que as áreas com maior concentração de areia fina encontram-se dentro do Parque ou mais próximo, como foi demonstrado nos pontos (1), (2) e (5). Neste último (5), somente a sua última camada continha maior teor de areia fina.

Em geral, observou-se a concentração maior da fração silte. Nos pontos ao redor do Parque, a maioria apresentou índices bem baixos, já nos mais próximos observou-se valores mais altos. Já quanto aos totais de fração argila, com relação ao gráfico (Fig. 10) podemos observar que foram altos, exceto nos pontos (4) e (5), constatando-se perfis argilosos.

\section{CONCLUSÃO}

A análise desenvolvida na área de estudo demostrou que vários são os aspectos que influenciam no "modelado" do Parque Natural Municipal Serra dos Parecis, desde os simples processos intemperizadores, que acontecem diariamente, modelando-o por meio de mediadores básicos como: a água, o vento, a temperatura e a atuação da vegetação, como também processos morfoestruturais de origem tectônica.

Todos esses aspectos influenciam na morfoestrutura e na morfoescultura do Parque, ocasionados por processos superficiais de origem erosiva como também processos mais complexos como a influência aluvial promovida pelo rio Mamoré ao longo de sua trajetória.

Infere-se, portanto, que essa influência aluvial, advinha do rio Mamoré, verificada nas análises granulométricas considerada nos pontos (1), (2), (3), (4) e (5), onde 65,24\% de todo o solo analisado, é composto de areia. Portanto, o Parque e seu entorno são compostos, significativamente, de areia em suas coberturas superficiais (até $60 \mathrm{~cm}$ ). Razão disto, concluise que a área de estudo já apresentou cobertura fluvial, sendo hoje, constituída de material de origem aluvial, somada a material detrítico (seixos) produto da decomposição das rochas.

Pode-se inferir, ainda, por meio das análises e observações das imagens de satélites, que a drenagem temporária do Parque é de extrema importância na formação das camadas de materiais intemperizados, uma vez que essa drenagem basculha as partículas de rochas intemperizadas para o sopé da vertente, interferindo na forma do pedimento existente entre o Parque e o rio Mamoré. 
Esse trabalho traz contribuição fundamental para melhor compreender os aspectos geomorfológicos da Serra dos Pacaás Novos (Parque Municipal Natural dos Parecis), por ser ambiente carente de investigação. Evidenciou-se tal situação no decorrer da pesquisa bibliográfica. Porém, é estimulante e satisfatório tal contribuição científica em um lugar de beleza natural e de grande geobiodiversidade, contribuindo para o aprofundamento das discussões acerca da utilização racional de suas potencialidades.

\section{REFERÊNCIAS}

CHRISTOFOLETTI, A. Geomorfologia. 2 ed. São Paulo: Edgard Blucher, 1980.

EMBRAPA. Manual de métodos de análise de solo/ Centro Nacional de Pesquisa de Solos. 2. ed. rev. atual. - Rio de Janeiro, 1997.

FLORENZANO, T. G. (org.). Geomorfologia: conceitos e tecnologias atuais. São Paulo: Oficina de textos, 2008. Cap. 1.

GUERRA, A. J. T; CUNHA, S. B. (Orgs.) Geomorfologia: uma atualização de bases e conceitos. Rio de Janeiro: Bertrand Brasil. 1994.

IBGE. INSTITUTO BRASILEIRO DE GEOGRAFIA E ESTATÍSTICA. Estado de Rondônia - Geologia. 1 ed. 2006 (mapa geológico)

IBGE. INSTITUTO BRASILEIRO DE GEOGRAFIA E ESTATÍSTICA. Estado de Rondônia - Geomorfologia. 1 ed. 2006 (mapa geomorfológico)

IBGE. INSTITUTO BRASILEIRO DE GEOGRAFIA E ESTATÍSTICA. Mapa de Solos do Brasil. 2001.

IBGE. INSTITUTO BRASILEIRO DE GEOGRAFIA E ESTATÍSTICA. Estado de Rondônia - Pedologia: Mapa exploratório de solos. 1 ed. 2006.

LATRUBESSE, M. E. Paleo e neoclimas da Amazônia Sul-Ocidental. Southwestern Amazônia Paleo And Neoclimates. Paleo y Neo Climas da Amazônia Sudoccidental. Rio Branco: UFAC/Laboratório de Geomorfologia e Sedimentologia. 1996.

BRASIL. Ministério do Meio Ambiente. Instituto Chico Mendes de Conservação da Biodiversidade. Revisão Do Plano De Manejo Do Parque Nacional De Pacaás Novos. Brasília. $\quad 2009 . \quad$ ICMBIO. Disponível em: https://www.icmbio.gov.br/portal/images/stories/imgs-unidadescoservacao/parna pacaas novo.pdf. Acesso em: 10 out. 2019.

PENTEADO, M. M. Fundamentos de geomorfologia. 2. ed. Rio de Janeiro: IBGE, 1978. $180 \mathrm{p}$. 
PRESS, F.; GROTZINGER, J.; SIEVER, R.; JORDAN, T. H. Para Entender a Terra. Tradução: MENEGAT, R. (coord.). 4 ed. Porto Alegre: Bookman, 2006.

RANZANI, G. Recursos Pedológicos da Amazônia. Acta Amaz., v. 9, n. 4, supl. 1. Manaus. P. 23-35, 1979.

ROSS, J. L. S. O Relevo Brasileiro: uma nova proposta de classificação. Revista do Departamento de Geografia, p. 25-39, 1985. Disponível em: http://www.periódicos.usp.br.

ROSS, J. L. S. Geografia do Brasil. 5 ed. rev. e ampl. - São Paulo: Editora da Universidade de São Paulo, 2005.

ROSS, J. L. S (org). Geografia do Brasil. São Paulo: Edusp 2011, p. 54,55 e 63 (Didática 3).

RAMALHO, R. Projeto Noroeste de Rondônia - Geomorfologia - Relatório Preliminar. CPRM, 1980

RODRIGUES, T. E; PALMIERI, F.; CAMARGO, M. N.; JACOMINE, P. K. T.; OLMOS, J.; SANTOS, I. L. R. D.; SILVA, J. M. L.; SANTOS, P.L. Estudo Expedido de Solos do Território Federal de Rondônia para fins de classificação, correlação e legenda preliminar. Rio de Janeiro. EMBRAPA/SNLCS, 1980 (Boletim técnico, 73).

SOUZA, E. C.; MELO, A.F.F.; ADAMY, A.; SOEIRO, R. J.; DALEIRO, V. Projeto Noroeste de Rondônia, Geomorfologia. Relatório final. CPRM. 1980.

SILVA, L.M.; PARENTE, C.V.; BRANDÃO, R.L.; ARAUJO, R.V.; ROMANI, S. J.; CAVALCANTE, J.C. Projeto Guajará-Mirim. Relatório final. V.1. DNPM - CPRM. 1980.

TEIXEIRA, W.; TOLEDO, C.; FAIRCHILD, T.; TAIOLI, F. Decifrando a Terra. São Paulo: Oficina de Textos, 2000.

TORRES, F.T.P; MARQUES NETO, R.; MENEZES, S.O. Introdução à Geomorfologia. São Paulo: CENGAGE, 2013. 